\title{
The Effects of Aerobic Exercise on Pulmonary Indexes in Obese Women from Iran
}

\author{
Mona Abdolhamid Tehrani, Rohollah Valizadeh, Mehdi Zarghami
}

\begin{abstract}
Background: The aim of this research was to assess effect of 8 weeks aerobic exercise on pulmonary indexes of force vital capacity (FVC) and force expiratory volume in one second (FEV1) in obese women.
\end{abstract}

Methods: Initially, a total 200 women of National Iranian South Oil Company (name of the place) were enrolled in this study. Subsequently, 40 women with body mass index ranging from 25 to 29.9 were selected as study population. The study population was devided in 2 groups, each with 20 women. One group (experimental group) performed aerobic exercise for 8 weeks and the other group did not perform any specific physical exercise. FVC and FEV1 were measured in all subjects before the commencement of the study and after the end of the study.

Results: The age of the subjects ranged from 40 to 50 years. There was no significant difference in values of FVC and FEV1 between experimental study population and control group at start of the study. However, the levels of both FVC and FEV1 increased significantly in experimental group compared to control group.

Discussion: Aerobic exercise seems to have an effect on pulmonary function of obese Iranian female.

Abbreviations: FVC: Force vital capacity; FEV1: Force expiratory volume in one second; BMI: Body mass index; MHR: Maximum heart rate; NICOS: National Iranian South Oil Company.

Keywords: Aerobic exercise, FVC, FEV1, Obese women, Iranian.

How to cite this article: Tehrani MA, Valizadeh R, Zarghami M. The Effects of Aerobic Exercise on Pulmonary Indexes in Obese Women from Iran. Euroasian J Hepato-Gastroenterol 2012; 2(1):28-29.

\section{Source of support: Nil}

\section{Conflict of interest: None}

\section{BACKGROUND}

Overweight and obesity represent one of major social and public health problems in global context. The complications of obesity such as cardiovascular diseases, diabetes mellitus, coronary diseases and stroke have reached epidemic proportions in the world. Recently, American National Health and Nutrition has shown that 6 to $61 \%$ of American adult populations suffer from gaining weight and obesity phenomena. Also, the trend is on increase in global perspective. ${ }^{1}$ Studies have shown that obese people mortalities are 25 to $75 \%$ more than normal ones. Also, it is also seen that obesity-related complications increase with age. People aged 45 to 50 years will suffer from increased mortality than normal ones if they have $13.5 \mathrm{~kg}$ overweight and they will suffer $56 \%$ more mortality than normal ones if they have $23 \mathrm{~kg}$ overweight. Obesity could be led to dyspnea through decrease in vital capacity of lungs because of pulmonary compliance limitation and due to lipid sedimentation in abdomen wall and thorax, so that people with long- run obesity would suffer pulmonary emphysema which is irreversible by losing weight. ${ }^{2}$ Increase in physical exercise, on the other hand, could help increase in pulmonary function and decrease in fat percentage. In this study, we assessed the impact of exercise on force expiratory volume in 1 second (FEV1) and force vital capacity (FVC)) on type I obese women aged 40 to 50 years in Iran.

\section{METHODS}

Initially, a total of 200 women of National Iranian South Oil Company, Iran were selected for the study. The age of the subjects ranged from 40 to 50 years. Subjects with body mass index (BMI) ranging from 25 to 29.9 were included in the final study. These 40 women referring as type I obese people were subjected to measurement of FEV1 and FVC indices at the start of study (pretest assessment). These 40 women were divided into two groups, each compromising of 20 women. The experimental group did running aerobic exercise of 60 to $70 \%$ severity, in maximum heart rate (MHR), 3 times a week for 30 minutes for 8 consecutive weeks. The rest 20 women of control group did not receive any exercise. Both FEV1 and FVC variables were measured at the end of 8 exercise weeks.

\section{RESULTS AND DISCUSSION}

The age of the women of both control and experimental group was almost similar, as mentioned. The BMI of the group of population also did not show any statistical variation. There was no significant difference in FEV1 and FVC between control and experimental group at the start of the study. However, the levels of both FEV1 and FVC increased significantly in experimental group receiving exercise compared to control group that did not provide any exercise $(p<0.05)$ (Fig. 1). 


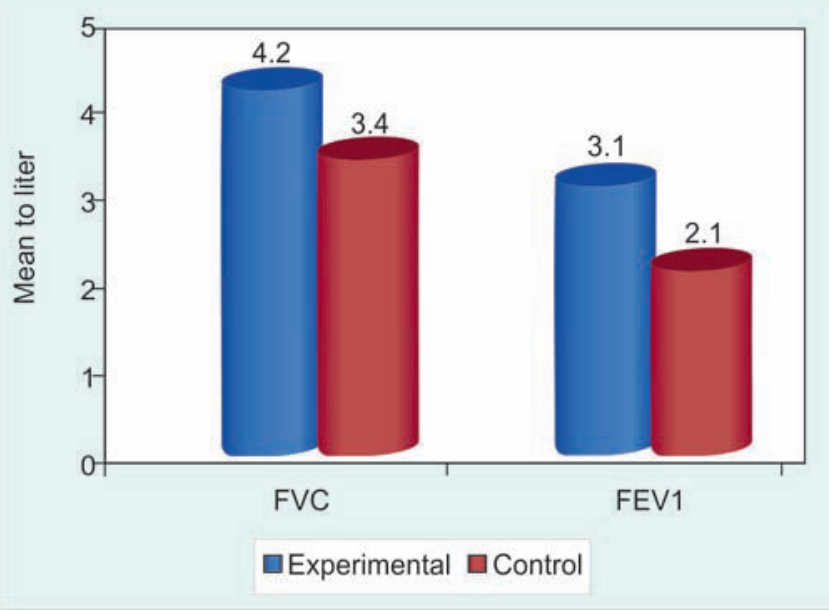

Fig. 1: Force vital capacity (FVC) and force expiratory volume in one second (FEVI), in study population

Respiratory system is important among vital body systems that work to exchange gases required for daily activities and human survival. Indeed, fat accumulation and overweight can negatively affect pulmonary function. ${ }^{1}$ This study showed that exercise has a positive impact on pulmonary functions in obese women. Thus, inspiring about exercise may be helpful to reduce respiratory complications in obese people.

\section{ACKNOWLEDGMENT}

I acknowledge the support of friends and colleagues of Islamic Azad University, Omidiyeh Branch, Iran for their cooperation.

\section{REFERENCES}

1. Kippelen P, Caillaud C, Robert E, Connes P, Godard P, Prefaut C. Effect of endurance training on lung function: A 1 year study. Br J Sports Med 2005;39:617-21.

2. Ochs-Balcom HM, Grant BJ, Muti P, Sempos CT, Freudenheim JL, Trevisan M, et al. Pulmonary function and abdominal adiposity in the general population. Chest 2006;129:853-62.

\section{ABOUT THE AUTHORS}

\section{Mona Abdolhamid Tehrani}

Department of General Physical Education, Omidiyeh Branch, Islamic Azad University, Omidiyeh, Iran

\section{Rohollah Valizadeh (Corresponding Author)}

Department of General Physical Education, Omidiyeh Branch, Islamic Azad University, Omidiyeh, Iran, Phone: 98-916-986-8067, Fax: 98652-322-2533, e-mail: valizadeh@iauo.ac.ir

\section{Mehdi Zarghami}

Department of Physical Education, Shooshtar Branch, Islamic Azad University, Shooshtar, Iran 